\title{
Пассивный залог как один из компонентов выражения информационной структуры в мансийском языке: данные верхнелозьвинского диалекта
}

Жорник Дарья Олеговна, Институт языкознания РАН, Высшая школа экономики; daria.zhornik@yandex.ru

Статья посвящена одному из средств выражения информационной структуры в мансийском языке - пассивному залогу. В работе используются современные данные верхнелозьвинского диалекта, собранные автором и его коллегами в ходе полевых исследований в 2017-2019 годах в деревни Ушма и Тресколье Ивдельского района Свердловской области. По итогам экспедиций был создан небольшой корпус мансийского языка, в котором был осуществлен поиск конструкций с пассивным залогом. Приводится краткий обзор взглядов предшественников на роль залога в мансийском языке. На полевом материале рассматривается функционирование информационной структуры в верхнелозьвинском диалекте, в котором задействованы, помимо залога, система субъектного и субъектно-объектного спряжения, а также падежное маркирование. Анализируются пассивные конструкции, образованные от непереходных, переходных и битранзитивных глаголов.

В результате анализа данных делается подтверждающий предыдущие исследования вывод о том, что пассивизация происходит для продвижения в позицию подлежащего наиболее топикального участника; вместе с тем формулируется предположение о том, что помимо собственно информационной структуры высказывания на выбор пассивного залога влияют и другие факторы, такие как одушевленность и референциальный статус участника ситуации. Рассматриваются случаи, в которых подлежащим пассивной конструкции оказывается не наиболее топикальный, а наиболее одушевленный или наиболее определенный персонаж. Высказывается предположение о том, что играть роль в выборе залога может не один из этих факторов, взятый по отдельности, а некоторое суммарное значение по данным трем параметрам. В перспективе необходима разработка формальной модели, которая могла бы учитывать тонкости механизма выбора залога в мансийском и, шире, обско-угорских языках.

Ключевые слова: мансийский язык, полевая лингвистика, информационная структура, глагольная морфология, пассивный залог, корпусная лингвистика

\section{PASSIVE VOICE AS A MEANS OF MARKING INFORMATION STRUCTURE IN MANSI: DATA FROM THE UPPER LOZVA DIALECT}

Daria O. Zhornik, Institute of Linguistics, RAS, Higher School of Economics; daria.zhornik@yandex.ru

This article is aimed at investigating the passive voice as one of the means of marking information structure. The data we use come from our own fieldwork among the Upper Lozva Mansi in 2017-2019 conducted in villages of Ushma and Treskolje of the Ivdel district of the Sverdlovsk oblast, Russian Federation. The data gathered during field trips was assembled into a small corpus of the Northern Mansi language, and we extracted all examples of passive voice found in this corpus. In the article, we briefly summarize the views of our predecessors on the role of the passive voice in Ob-Ugric languages and afterwards we describe the general outline of information structure in Mansi by briefly depicting the use of subject and object conjugations, the passive voice and case marking. We separately analyze the passive voice constructions formed from intransitive, transitive and bitransitive verbs.

We conclude that passive voice is, as stated in previous studies, used for promoting the most topical constituent to the subject position. However, we also suppose that there are some other factors that contribute to the choice of voice in Mansi, e. g. animacy and referential properties of the constituent in question. We describe cases in which the most animate or the most definite (and not the most topical) constituent is being promoted to the subject position. We also suppose that not only these factors may separately affect the choice of voice, but also that the sum of these parameters might be crucial. We suggest that it is necessary to create a formal model which would include all the above-mentioned parameters and adequately describe the choice of voice in Mansi and in Ob-Ugric.

Keywords: the Mansi language, field linguistics, information structure, verbal morphology, passive voice, corpus linguistics

Сбор материала и работа над статьей велись в рамках работы по проекту РНФ № 19-78-10139 «Аргументная структура, залог и актантная деривация в языках Западной Сибири» (руководитель проекта - Д. А. Рыжова). 


\section{Введение ${ }^{1}$}

Мансийский язык (< обско-угорские < финно-угорские < уральские) распространен на территории ХМАО-Югры и Свердловской области и насчитывает около 1000 носителей (938 по переписи 2010 г.). В тексте настоящей статьи под наименованием «мансийский язык» мы будем понимать лишь северную группу его диалектов, поскольку остальные диалектные группы на данный момент уже не имеют живых носителей. Данные для статьи получены в ходе экспедиций автора, С. В. Покровской и В. С. Харитонова к носителям верхнелозьвинского диалекта в д. Ушма Ивдельского района Свердловской области в 2017-2019 гг. В Ивдельском районе существует несколько мансийских деревень, в которых носители всех поколений свободно владеют мансийским языком как родным и используют его практически как единственный язык повседневного общения. В связи с этим в экспедициях удается собирать большие объемы текстов различных жанров от носителей разных возрастных групп — нарративы, диалоги, экспериментальные тексты с выполнением тех или иных заданий.

B мансийском языке наблюдается порядок слов SOV, имеется шесть падежных граммем (номинатив, латив, локатив, аблатив, инструменталис, транслатив ${ }^{2}$ ) у существительных, а также «аккузатив» у личных местоимений, образующийся с помощью присоединения к основе местоимения посессивного показателя того же лица и числа. В языке представлены субъектное и субъектно-объектное спряжение, распространен пассивный залог, о котором и пойдет речь в настоящей работе. Следует отметить, что в мансийском языке невозможно никакое согласование с косвенным объектом, а в пассивном залоге возможны только формы субъектного спряжения.

Пассивные конструкции в мансийском языке образуются с помощью присоединения к финитному глаголу одного из алломорфов пассивного показателя -we, при этом глагольное согласование контролирует участник, продвинутый в позицию подлежащего, а участник, с этой позиции смещенный, может либо не иметь поверхностного выражения, либо маркироваться лативом или, реже, инструменталисом механизм выбора падежного маркера будет кратко описан далее.

(1) $\bar{a} 6-u m \quad t i-t \quad k o l \quad \bar{u} n t-t-\partial s^{3}$

отец-POSS.1SG этот-LOC дом сесть-TR-PST[3SG]

'Мой отец построил здесь дом'.

(2) $t i-t \quad k o l$ ünt-t-awe-s

этот-LOC дом сесть-TR-PASS-PST[3SG]

'Здесь построили дом'.

\section{(3) $t i-t \quad k o l \quad \bar{a} 6-u m-n a \quad \bar{u} n t-t-a w e-s$}

этоT-LOC дом отец-POSS.1SG-LAT сесть-TR-PASS-PST[3SG]

'Моим отцом построен здесь дом'.

Пассивные конструкции в обско-угорских (хантыйском и мансийском) языках обладают некоторыми особенностями: они характеризуются высокой частотностью и во многом не попадают под типичные определения пассивного прототипа ([Shibatani 1985; Keenan, Dryer 2006] и др.), поскольку в позицию подлежащего в пассивной конструкции может продвигаться не только «исходное» ${ }^{4}$ прямое дополнение,

${ }^{1}$ Автор выражает благодарность В. С. Харитонову, В. А. Плунгяну, А. Ю. Урманчиевой и Н. А. Муравьёву за консультации по вопросам, поднимающимся в данной работе, а также анонимным рецензентам за советы, касающиеся библиографии по теме статьи, и другие ценные замечания.

2 Здесь и далее мы используем условные ярлыки для обозначения падежей. Наиболее важными для данной статьи являются падеж на - $n$ («латив») и падеж на -l («инструменталис»).

3 Здесь и далее примеры представлены в условной фонематической записи, разработанной участниками проекта по документации мансийского языка. В ней используется символ 6 для обозначения палатального фрикатива, сложная велярная лабиализованная фонема обозначается сочетанием символов $k w$, для обозначения фонологической долготы гласных используется макрон.

${ }^{4}$ В исследованиях пассивного залога довольно типична стратегия, при которой пассивную и активную формы рассматривают как симметричные друг другу конфигурации, и при анализе пассивной конструкции ей зачастую сопоставляют «аналогичную» активную. В данном разделе для упрощения мы тоже следуем этой стратегии, однако мы не считаем ее достаточно адекватным способом описания мансийских пассивных конструкций. Мы сомневаемся в тесном взаимодействии залога и переходности в мансийском языке и не считаем, что для каждой пассивной конструкции возможно восстановить зеркальный активный вариант. См. также аналогичные соображения в [Скрибник 2004: 454]. 
но и другие аргументы глагола (например, участники с ролью Реципиента, Бенефактива, Места или Цели, см. [Kulonen 1989]), то есть пассивизироваться могут и непереходные глаголы.

(4) $\bar{a}_{6}$-um am palt-um joxt-əs

отец-POSS.1SG 1SG к-POSS.1SG прийти-PST[3SG]

'Мой отец пришел ко мне'.

(5) am ä $\bar{a}_{6}$-um-na joxt-uwe-s-um

$1 \mathrm{SG}$ отец-POSS.1SG-LAT прийти-PASS-PST-1SG

'Мой отец пришел ко мне'.

Исследования обско-угорского и, специальнее, мансийского залога начинаются еще с трудов [Bouda 1936; Lavotha 1960]. Одной из основных работ по этой теме является диссертация [Kulonen 1989]; эта проблематика обсуждается также в таких работах, как [Ромбандеева 1979; Honti 1982; Schiefer 1985; Skribnik 2001; Скрибник 2004].

В предыдущих исследованиях представлено два основных типа определений обско-угорского залога. С одной стороны, важной оказывается топикальность участников ситуации. В позицию подлежащего продвигается наиболее топикальный аргумент, см. следующие определения:

а. Страдательный залог... служит для поддержания тематической доминанты текстового фрагмента [Кошкарёва 2002: 35];

b. Passive [involves] the demotion of the [-topic] highest argument... and the promotion of a [+topic] internal argument (if there is one)... [Kiss 2019: 163] («В ходе пассивной деривации происходит понижение аргумента со значением [-топик] ... и продвижение внутреннего аргумента со значением [+топик]...»; перевод здесь и далее наш. - Д. Ж.)

С другой стороны, пассивный залог определяют через несоответствие топика и Агенса: в случае, когда наиболее топикален неагентивный участник, используется пассив:

c. ... a more important factor in the use of the passive is the idea of the non-agentivity of the topic, the grammatical subject of the sentence [Kulonen 1989: 71] («Более важный фактор в использовании пассива — это идея неагентивности топика, грамматического субъекта предложения»);

d. ...passive construction arises when the topic... does not correspond to the semantic role of agent [Nikolaeva 2001: 16] («Пассивная конструкция возникает, когда топик... не соотносится с семантической ролью Агенса»).

Основная задача настоящего исследования - очертить круг явлений, не подпадающих под гипотезу о продвижении в позицию подлежащего наиболее топикального участника, и выдвинуть предположения о том, какие еще факторы могут играть роль при выборе залога в мансийском языке.

Работа устроена следующим образом. В разделе 1 рассматривается информационная структура в мансийском языке, в разделе 2 подробно обсуждаются мансийские пассивные конструкции. В заключении суммируются основные выводы работы.

\section{1. Информационная структура в мансийском языке}

В обско-угорских языках наблюдается сложная система регулирования информационной структуры, которая задействует различные средства: субъектное и объектное спряжения, пассивный залог, падежное маркирование, дискурсивные частицы, просодическое маркирование. В настоящей статье мы не будем касаться последних двух компонентов и очертим механизм выбора типа спряжения и залога в мансийском языке.

В данной статье, как и в работах предыдущих исследователей, мы будем в основном опираться на понимание информационно-структурных единиц по [Lambrecht 1994], а также по [Nikolaeva 2001]. В paботе [Lambrecht 1994] топик и фокус понимаются следующим образом. Топик - "whatever the proposition is about" («то, о чём пропозиция», [Lambrecht 11994: 118]), а фокус — "the semantic component of a pragmatically structured proposition whereby the assertion differs from the presupposition" («семантический компонент прагматически структурированной пропозиции, которым ассерция отличается от пресуппозиции», [Lambrecht 1994: 213]). В работе [Nikolaeva 2001] в дополнение к предыдущим понятиям вводится так называемый вторичный топик для описания топикального прямого объекта. В некоторых случаях важным оказывается и понятие контрастивного топика (см., например [Aissen 2015]), который описывает те случаи, когда в дискурсе топик содержит в себе альтернативы, см. [Krifka 2008]. 
Информационно-структурные механизмы в северномансийском языке обсуждались в таких работах, как [Ромбандеева 1979; Скрибник 2004], а также на восточномансийском материале в трудах Сюзанны Виртанен [Virtanen 2012, 2014, 2015]. Мы с некоторыми собственными дополнениями приведем ее анализ мансийской информационной структуры уже на северномансийском материале, а в следующем разделе более детально исследуем поведение конкретно пассивного залога в этой системе.

С. Виртанен, используя вышеперечисленные понятия по [Lambrecht 1994] и [Nikolaeva 2001], описывает систему коммуникативного ранжирования участников высказывания, в которую встраивает переходность, объектное и субъектное спряжения и, наконец, в некоторых случаях пассивный залог. Основная идея такого подхода заключается в том, что в мансийском языке для основного топика зарезервирована синтаксическая позиция подлежащего, а в синтаксической позиции прямого дополнения могут оказываться именные группы, находящиеся либо в фокусе, либо во вторичном топике, см. [Virtanen 2015: 59], а также [Скрибник 2004: 48] про тему первого и второго ранга и рему ${ }^{5}$ В случае, если такая именная группа находится в фокусе, делается выбор в пользу субъектного спряжения, как в (6). Если же прямое дополнение представляет собой вторичный топик (а в фокусе, таким образом, оказывается лишь сам предикат), то глагольное согласование с ним будет маркировано объектным спряжением, как в (7).

(6) am akw xūl puw-s-um

1SG один рыба поймать-PST-1SG

'(Я сходил на рыбалку и) поймал одну рыбу'.

(7) am ti $x \bar{u} l$ puw-os-l-um

1SG этот рыба поймать-PST-SG.O-1SG.S

'(Я очень долго хотел поймать одну конкретную рыбу, всем об этом рассказывал и) я эту рыбу поймал’.

По корпусным данным прослеживается отчетливая тенденция, в соответствии с которой личные местоимения в позиции прямого дополнения требуют объектного согласования всегда, поскольку в корпусе не встретилось примеров, в которых местоимение в позиции прямого дополнения было бы в фокусе. Однако опрос носителей показал, что, если поместить местоимение в фокус, будет употребляться субъектное спряжение:

(8) a. pēt'a tūp anum ērupt-i

Петя только 1SG.OBL любить-NPST[3SG]

'Петя только меня любит'.

b. *pēt'a tūp anum èrupt-i-t-e

Петя только 1SG.OBL любить-NPST-SG.O-3SG.S

Ожидаемое значение: 'Петя только меня любит'.

Если же Пациенс, а не Агенс оказывается основным топиком, выбирается пассивная конструкция. Тогда «бывшее» прямое дополнение продвигается в позицию подлежащего. Так, в (9) позицию подлежащего занимает главный герой рассказа (являющийся основным топиком), который оказывается унесен волком в лес.

(9) ta tot-we-s wōr-ēen

PTCL нести-PASS-PST[3SG] лес-POSS.3SG-LAT

'И вот он унес его в лес'.

Заметим, что в этом примере Агенс ${ }^{6}$ (волк) при пассиве не выражен (Пациенс также не выражен, но контролирует глагольное согласование). Как правило, именно это мы наблюдаем при достаточно высокой степени активации Агенса, нуль-анафора является наиболее частым способом референции к наиболее активированным участникам. Однако, если Агенс находится в фокусе, он может быть выражен в поверхностной структуре при помощи латива.

${ }^{5}$ По-видимому, в работе Е. К. Скрибник под понятиями темы первого ранга и ремы подразумеваются как раз понятия топика и фокуса по [Lambrecht 1994], а под понятием темы второго ранга - вторичный топик по [Nikolaeva 2001].

${ }^{6}$ Поскольку в этом разделе мы не хотим вдаваться в подробности, используется некоторое упрощение, и подлежащее любого переходного глагола мы называем Агенсом (а прямое дополнение - Пациенсом), хотя в мансийском существуют и неагентивные переходные глаголы (например, видеть и мн. др.). 


ta tot-we-s wōr-e-en $n \quad \boldsymbol{x a j j t - n - u t - n a}$

PTCL нести-PASS-PST[3SG] лес-POSS.3SG-LAT бежать-PTCP-вещь-LAT

'А волк (букв. «бегающая штука») его в лес-то и унес'.

Если в позиции исходного подлежащего находится не одушевленный деятель, а, например, неодушевленный Эффектор ${ }^{7}$, то предпочтительным оказывается его маркирование не лативом, а инструменталисом, хотя латив, как показал опрос носителей, также возможен:

(11) āwi wōt-na / wōt-əl pālif=wōt-amt-awe-s

дверь ветер-LAT / ветер-INS врозь=ветер-ASP-PASS-PST[3SG]

'Ветром дверь настежь раскрыло'.

Таблица 1. Соответствие структурных позиций и информационной структуры в конструкциях с двумя участниками

\begin{tabular}{|c|c|c|}
\hline & Агенс & Пациенс \\
\hline $\begin{array}{l}\text { Основной топик } \\
\text { (ОT) }\end{array}$ & $\begin{array}{l}\text { подлежащее } \\
\text { немаркированная форма } \\
\text { активный залог } \\
\text { субъектное согласование }\end{array}$ & $\begin{array}{l}\text { подлежащее } \\
\text { немаркированная форма } \\
\text { пассивный залог } \\
\text { субъектное согласование }\end{array}$ \\
\hline $\begin{array}{l}\text { Вторичный топик } \\
\text { (BT) }\end{array}$ & - & $\begin{array}{l}\text { прямое дополнение } \\
\text { немаркированная форма / «аккузатив» } \\
\text { у личных местоимений } \\
\text { активный залог } \\
\text { объектное согласование }\end{array}$ \\
\hline Фокус (Ф) & $\begin{array}{l}\text { косвенное дополнение } \\
\text { латив / инструменталис } \\
\text { пассивный залог }\end{array}$ & $\begin{array}{l}\text { прямое дополнение } \\
\text { немаркированная форма } \\
\text { активный залог } \\
\text { субъектное согласование }\end{array}$ \\
\hline
\end{tabular}

Если при пассивизации переходных конструкций появление латива гораздо более ожидаемо и частотно, чем появление инструменталиса, то в дитранзитивных конструкциях мы можем с достаточной частотой наблюдать оба эти падежа. Дитранзитивные конструкции в мансийском языке, помимо работ С. Виртанен, были описаны в работах [Kulonen 1999; Bíró, Sipőcz 2017, 2018], также эта тема затронута в работе [Ромбандеева 1979].

Для упрощения будем считать, что в дитранзитивной ситуации имеются Агенс, Тема и Реципиент. Мы не будем приводить примеры на все возможные комбинации семантических ролей и информационно-структурных статусов, но отметим, что участник, являющийся основным топиком, будет попрежнему занимать позицию подлежащего, вторичным топиком - прямого дополнения, фокусом дополнения в лативе или инструменталисе, при этом латив используется в основном для маркирования одушевленного участника, а инструменталис - для неодушевленного участника, см. грамматичность примеров (12) - (13) и запрет примеров (14a) и (14b). Особым случаем является ситуация с неодушевленным Реципиентом - конечной точкой, в этом случае по-прежнему происходит ее маркирование лативом, то есть в дитранзитивных конструкциях на маркирование участников влияют как семантическая роль участников (в случае Реципиента / Конечной точки), так и их одушевленность (в случае с Темой).

(12) a. am pēt'a-n nēpak mi-s-l-um

1SG Петя-LAT книга дать-PST-SG.O-1SG.S

'Петя дал мне книгу'.

b. am pēt'a-n miét-um mi-s-l-um

1SG Петя-LAT младшая.сестра-POSS.1SG дать-PST-SG.O-1SG.S

'Я дал Пете мою младшую сестру (подержать)'.

7 Эффектор в мансийском языке может оказываться в позиции подлежащего в активном залоге и контролировать глагольное согласование: wōt awi paliy=puns-as ветер дверь настежь=открыть-PST[3SG] 'Beтер распахнул дверь’. 
(13) a. pēt'a nēpak-al mi-we-s

Петя книга-INS дать-PASS-PST[3SG]

'Пете дали книгу'.

b. am pēt'a mi-s-l-um nēpak-al

1SG Петя дать-PST-SG.O-1SG.S книга-INS

'Я дал Пете книгу'.

(14) a. *pēt'a ēe-um-tal mi-we-s

Петя младшая.сестра-POSS.1SG-INS дать-PASS-PST[3SG]

Ожидаемое значение: 'Пете дали мою младшую сестру (подержать)'

b. *am pēt'a mi-s-l-um ēe-um-tal

1SG Петя дать-PST-SG.O-1SG.S младшая.сестра-POSS.1SG-INS

Ожидаемое значение: 'Я дал Пете мою младшую сестру (подержать)'.

(15) ńawram-ət xan'ict-an ēkwa mujlupt-as iškola-n nēpak-ət ребенок-PL учить-PTCP женщина подарить-PST[3SG] школа-LAT книга-PL 'Учительница подарила школе книги'.

(16) a. am pij-na nēpak mi-s-l-um

1SG сын-LAT книга дать-PST-SG.O-1SG.S

'Я юноше (новая информация) (эту) книгу дал'.

b. am ti piy nēpak-al mi-s-l-um

1SG этот сын книга-INS дать-PST-SG.O-1SG.S

'Я этому юноше книгу (новая информация) дал'.

Таблицуа 2. Соответствие семантических ролей и информационной структуры в дитранзитивных конструкциях

\begin{tabular}{|c|c|c|c|}
\hline & Агенс & Тема & Реципиент \\
\hline \multirow[t]{3}{*}{ OT } & подлежащее & \multicolumn{2}{|c|}{ подлежащее } \\
\hline & немаркированная форма & \multicolumn{2}{|c|}{ немаркированная форма } \\
\hline & активный залог & \multicolumn{2}{|c|}{ пассивный залог } \\
\hline \multirow[t]{2}{*}{$\mathrm{BT}$} & & \multirow{2}{*}{\multicolumn{2}{|c|}{$\begin{array}{l}\text { прямое дополнение } \\
\text { немаркированная форма } \\
\text { активный залог } \\
\text { объектное согласование }\end{array}$}} \\
\hline & - & & \\
\hline \multirow[t]{3}{*}{$\Phi$} & косвенное дополнение & косвенное дополнение & косвенное дополнение \\
\hline & латив & инструменталис & латив \\
\hline & пассивный залог & активный залог & активный залог \\
\hline
\end{tabular}

Обобщим кратко функции субъектного и объектного спряжений, пассивного залога и падежного маркирования периферийных участников. Позиция подлежащего в мансийском зарезервирована для основного топика, прямого дополнения с объектным согласованием - для вторичного топика, дополнения в лативе / инструменталисе - для фокуса. Таким образом, субъектное спряжение в переходном глаголе используется для постановки в фокусную позицию второго участника в переходной ситуации, пассивный залог - для его постановки в позицию основного топика. Латив и инструменталис используются для маркирования фокусного участника в пассивной и дитранзитивной конструкциях, при этом выбор падежа определяется семантической ролью, а в случае Темы - одушевленностью.

\section{2. Пассивный залог в верхнелозьвинском диалекте мансийского языка}

Для настоящей работы был проанализирован расшифрованный фрагмент экспедиционного корпуса текстов на верхнелозьвинском диалекте (mansi.pro/corpus/search), состоящий на момент написания данной статьи приблизительно из 18227 словоформ (примерно 2513 предложений). В корпусе было обнаружено 189 пассивных конструкций. Некоторые примеры, представленные в данной работе, были получены в ходе опроса носителей верхнелозьвинского диалекта. 
Рассмотрим различные типы пассивных конструкций, встреченных в верхнелозьвинском корпусе. Наиболее частотны в обработанном материале конструкции, образованные от переходных глаголов (137; переходными мы считаем те глаголы, которые имеют в активной конструкции формы объектного спряжения), затем следуют конструкции, образованные от непереходных глаголов (45), и наименее частотны конструкции, образованные от битранзитивных глаголов (7). Битранзитивные конструкции мы в данной работе не рассматриваем ввиду малого количества найденных в корпусе примеров.

Глаголы, встречающиеся в пассивных конструкциях, образованных от переходных глаголов, отличаются наибольшим разнообразием. Это могут быть непроизводные основы, каузативные глаголы, глаголы с различными аспектуальными показателями, конструкции со вспомогательными глаголами. В подавляющем большинстве случаев в позиции подлежащего мы видим наиболее топикального участника: так, пример (17) относится к рассказу носителя о себе, в котором референт 'я' обладает следующими особенностями: а) референт первого лица оказывается выше всех в референциальной иерархии; б) он является протагонистом рассказа; в) наиболее активирован; г) именно в этом предложении он является топиком по [Lambrecht 1994]. В примере (18) речь также идет о некотором протагонисте, который женится на мифической женщине Миснэ, при этом, когда он перестает быть Агенсом и становится Пациенсом, мы наблюдаем использование пассивного залога (см. использование активного залога в предтексте). По [Lambrecht 1994] и 'он', и ‘Миснэ' оказываются топикальными, однако по [Givón 1983] ‘он' более активирован, поскольку весь непосредственно предшествующий дискурс идет о 'нем', а также 'он' является протагонистом рассказа.

(17) $k$ wäl-tt-uwe-s-um rug piz-na встать-CAUS-PASS-PST-1SG русский сын-LAT '(Сегодня утром я рано встал.) Русский парень меня разбудил'.

(18) jomas taj xum jomas misne tot-i хороший этот мужчина хороший Миснэ нести-NPST[3SG]

a ta misne-tēen wērm-awe wōr-n tot-ujkw

а тот Миснэ-POSS.3SG-LAT мочь-PASS[NPST.3SG] лес-LAT нести-INF

'(Куда бы он ни пошел, всё добывает постоянно, зверей добывает.) Вроде хорошо, что он на Миснэ женится. А эта Миснэ его может в лес увести'.

Также укладываются в теорию о продвижении наиболее топикального участника и пассивные примеры, образованные от непереходных глаголов (то есть глаголов, не имеющих форм объектного спряжения в активном залоге), см. пример (19a). Здесь в позицию подлежащего продвигается участник, который в активной конструкции был бы выражен послеложной группой, см. (19b).

(19) a. xājtnut-n nēell-ap-awe-s-uw

волк-LAT появиться-PFV-PASS-PST-1PL

'(Мы пешком шли, чай пили в одном месте, и тут, когда немного осталось,) волки встретились нам (букв. 'мы появились волком')'.
b. $\boldsymbol{m} \bar{a} \boldsymbol{n}$ èl-i-palt-uw
xājtnut nēyl-ap-as
$1 \mathrm{PL}$ перед-ATTR-к-POSS.1PL волк появиться-PFV-PST[3SG]
'Нам встретился волк'.

Периодически при пассиве от непереходных глаголов в мансийском языке встречается малефактивная семантика, как в примере выше - участник 'мы' испытывает негативное воздействие от появления участника 'волк'. То же самое наблюдается и в случае с глаголами движения:

(20) mān xōnt-n ta joxt-awe-w

1PL войско-LAT PTCL прийти-PASS[NPST]-1PL

'На нас войско идет'.

В подобных случаях обычно говорят о так называемом адверсативном пассиве, см., например, [Wierzbicka 1979]. Хотя наиболее известные работы об этом явлении посвящены такому языку, как японский ([Kortland 1992; Tsuboi 2010; Toyota 2011]), адверсативный пассив распространен и в Северной Евразии, например в эвенском [Malchukov 1993], также подобные конструкции представлены в близкородственном мансийскому хантыйском [Муравьёв, в печати].

В целом приведенные выше примеры хорошо вписываются в предложенную в разделе 1 картину, в которой в позиции подлежащего оказывается наиболее топикальный участник, то есть находящийся 
в позиции топика по [Lambrecht 1994], а также наиболее активированный по [Givón 1983]. Однако в корпусе были обнаружены и примеры типа (20), в котором пассив используется в первом предложении текста, то есть в тетическом предложении, которое полностью находится в фокусе по [Lambrecht 1994]. Можно предположить, что референт 'санквылтап' (мансийский музыкальный инструмент) является топиком по одной из мер по [Givón 1983] — катафорической значимости, то есть в дальнейшем повествовании он становится топиком.

(20) sāykwaltap jīw-al wär-awe

санквылтап дерево-INS делать-PASS[NPST.3SG]

'Санквылтап делают из дерева'.

Еще более спорным оказывается пример (21). В данной ситуации Тема - новый референт и находится в аддитивном фокусе. Ранее 'свадьба' в тексте не упоминалась. Тем не менее, используется пассивный залог.

(21) tuwal os pūri wār-awe pūri

потом ADD свадьба делать-PASS[NPST.3SG] свадьба

'(Потом в семье тоже еще праздник устраивают, когда ребенок рождается.) Потом еще свадьбу делают, свадьбу'.

На наш взгляд, выбор залога в данных случаях обусловлен пониженными референциальными свойствами Агенса. В случае, если Агенс генерический или неопределенный, будет использоваться пассивный залог, вне зависимости от свойств Пациенса, см. пример (22) с неопределенным Агенсом:

(22) isnas pus-we-s

окно открыть-PASS-PST[3SG]

‘(Что случилось?) Кто-то открыл окно’.

Помимо референциального статуса Агенса, важен также референциальный статус Пациенса. В примере (23) топикальны все участники, однако уникален среди них только референт 'волк' — именно он продвигается в позицию подлежащего, и используется пассив.

(23) saw 6iskurek-ət joxt-əs-ət волк puct-uwe-s

много курица-PL прийти-PST-3PL избить-PASS-PST[3SG]

'(Маленькие курицы к волку пришли, он их почти съел. Потом) много куриц пришло, волка избили’.

Выше мы рассмотрели ситуации, в которых Агенс референциально понижен либо уступает Пациенсу по референциальному статусу. Рассмотрим, однако, пример (24), в котором референт 'ветер' определенный и топикальный, а 'Маша' находится в позиции аргументного фокуса. Несмотря на такие свойства референтов, используется пассив, и в позицию подлежащего продвигается 'Маша'.

(24) $m \bar{a} \check{s} a$ wōt $-n \quad$ jol=pat-t-uwe-s

Маша ветер-LAT вниз=упасть-TR-PASS-PST[3SG]

'(Кого ветер сбил с ног?) Ветер сбил с ног Машу'.

Мы предполагаем, что в данном случае дело в одушевленности участников: в случае, когда выражены оба участника ситуации, приоритетная позиция отдается наиболее одушевленному из них. Эти соображения подтверждаются примером (25). В данной ситуации имеются все предпосылки для употребления пассивного залога, но используется актив. Референт 'стол' топикальный и определенный, а референт 'кто' - неопределенный и фокусный.

(25) ti pasan xot'ut jowt-os?

этот стол кто купить-PST[3SG]

(В комнате стоит новый стол.) 'Кто купил этот стол?'

Таким образом, мы предполагаем, что продвижение наиболее топикального участника в позицию подлежащего является лишь одной из функций мансийского пассивного залога, поскольку мы увидели в данном разделе некоторое количество примеров с информационно-структурным распределением, отличающимся от ожидаемого. Это заставляет предположить, что выбор залога регулируется не только информационной структурой, но и другими параметрами: референциальным статусом и одушевленностью. 


\section{Заключение}

В нашей работе мы рассмотрели предыдущие исследования пассивного залога и информационной структуры в мансийском языке, а также современные данные верхнелозьвинского диалекта. Ранее описание залога в обско-угорских языках производилось в первую очередь с точки зрения информационной структуры: в позиции подлежащего оказывается наиболее топикальный участник, и если это Пациенс, используется пассивный залог.

В предыдущем разделе мы сталкивались с примерами, в которых продвинутым в позицию подлежащего оказывался не наиболее топикальный участник, а либо менее топикальный, либо вообще новый, только что введенный референт. Эти наблюдения заставляют задуматься о том, что помимо топикальности существуют и другие факторы выбора залога, не связанные напрямую с информационной структурой.

На данный момент нами выявлены две дополнительные категории, оказывающие влияние на выбор залога в верхнелозьвинском диалекте мансийского языка: одушевленность и референциальный статус. Перспективным дальнейшим направлением исследований представляется углубленный анализ взаимодействия информационной структуры с этими параметрами. По предварительным данным, можно предположить, что выбор залога происходит в зависимости от как минимум трех признаков, характеризующих участников ситуации: топикальности, одушевленности и референциального статуса. Участник, который имеет наибольшее суммарное значение по этим параметрам, оказывается в позиции подлежащего. От этого выбора зависит использование активного и пассивного залога. Следующим шагом в нашем исследовании представляется формализация данного механизма в рамках некоторой новой модели и применение этой модели сначала к более широкому массиву мансийских данных, а затем, шире, к обско-угорскому материалу в целом.

Сокращения

\author{
1 - первое лицо \\ 3 - третье лицо \\ ADD - аддитивная частица \\ ASP - аспектуальный показатель \\ ATTR — атрибутив \\ CAUS - каузатив \\ INF — инфинитив \\ INS - инструменталис \\ LAT - латив \\ LOC - локатив \\ NPST - непрошедшее время
}

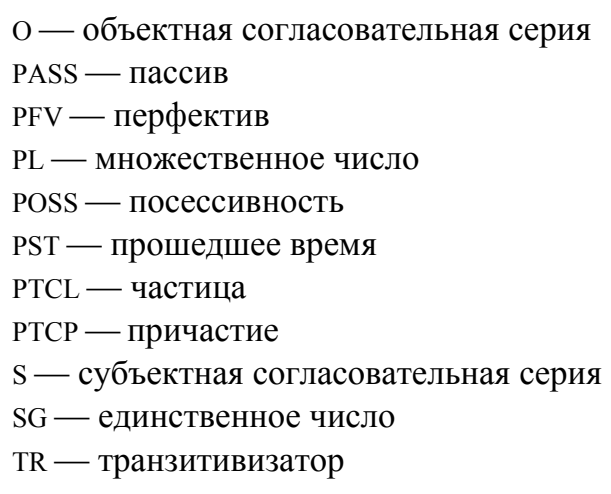

Литература

Кошкарёва 2002 - Кошкарёва Н. Б. Коммуникативная парадигма хантыйского предложения // Языки коренных народов Сибири. Новосибирск, 2002. С. 29-44. \{Koshkareva N. B. The communicative paradigm of the Khanty sentence // Languages of the indigenous people of Siberia. Novosibirsk, 2002. P. 29-44.\}

Муравьёв, в печати - Муравьёв Н. А. Адверсативный пассив от глаголов направленного движения в казымском диалекте хантыйского языка // Сибирский филологический журнал, в печати. \{Muravyev N. A. Adversative passive from verbs of directed motion in Kazym Khanty // Siberian Journal of Philology, to appear.\}

Ромбандеева 1979 - Ромбандеева Е. И. Синтаксис мансийского (вогульского) языка. Москва, 1979. \{Rombandeeva E. I. The syntax of the Mansi (Vogul) language. Moscow, 1979.\}

Скрибник 2004 - Скрибник $E$. K. Категории мансийского глагола и актуальное членение предложения // Типологические обоснования в грамматике. К 70-летию проф. В. С. Храковского. Москва, 2004. С. 445-458. \{Skribnik E. K. Categories of the Mansi verb and the information structure of the sentence // Typological explanations in grammar. Dedicated to the $70^{\text {th }}$ birthday of Prof. V. S. Khrakovsky. Moscow, 2004. P. 445-458.\}

Aissen 2015 - Aissen J. Documenting topic and focus. Presentation on the $4^{\text {th }}$ International Conference on Language Documentation and Conservation, University of Hawai'i (http://scholarspace.manoa.hawaii.edu/bitstream/handle/10125/ 25401/25401.pdf? sequence $=2$ ).

Biró, Sipöcz 2017 - Biró B., Sipöcz K. Ditransitivity in the Mansi language from typological perspective // FUM. 2017, 41. P. 25-43. 
Biró, Sipőcz 2018 - Biró B., Sipőcz K. Ditransitive constructions in Mansi dialects // Ditransitive constructions in a cross-linguistic perspective / Eds. A. Korn, A. Malchukov. Wiesbaden, 2018. P. 187-207.

Bouda 1936 - Bouda K. Das obugrische Passivum // Ungarische Jahrbücher 16. Berlin, 1936. P. 286 -293.

Givón 1983 - Givón T. Topic continuity in discourse: A quantitative cross-language study. Amsterdam — Philadelphia, 1983.

Honti 1982 - Honti L. Das Passiv in den obugrischen Sprachen // Acta Linguistica. Academiae Scientiarum Hungaricae. 1982. Vol. 32. № 1/4. P. 39-51

Keenan, Dryer 2007 - Keenan E. L., Dryer M. Passive in the world's languages // Syntactic Typology and Syntactic Description. Vol. 1: Clause structure / Ed. T. Shopen. Cambridge, 2007. P. 325-361.

Kiss 2019 - Kiss K. Fused grammatical and discourse functions in Ob-Ugric: Case, agreement, passive // Proceedings of the Workshop Clause Typing and the Syntax-to-Discourse Relation in Head-Final Languages / Eds. J. Bayer, Y. Viesel. Konstanz, 2019. P. 163-174.

Kortland 1992 - Kortlandt F. On the meaning of the Japanese passive // Acta Linguistica Hafniensia. 1992, 24.1. P. 97-108.

Krifka 2008 - Krifka M. Basic notions of information structure // Acta Linguistica Hungarica. 2008. Vol. 55. № 3-4. P. $243-276$.

Kulonen 1989 - Kulonen U.-M. The passive in Ob-Ugrian. Helsinki, 1989.

Kulonen 1999 - Kulonen U.-M. Über das Objekt der ditransitiven Konstruktionen im Wogulischen // Europa et Siberia. Beitrage zur Sprache und Kultur der kleineren finnougrischen, samojedischen und paläosibirischen Völker. Gedenkband für Wolfgang Veenker / Eds. C. Hasselblatt, P. Jääsalmi-Krüger. Wiesbaden, 1999. P. 265-272.

Lambrecht 1994 - Lambrecht $K$. Information structure and sentence form: Topic, focus and the mental representation of discourse referents. Cambridge, 1994.

Lavotha 1960 - Lavotha Ö. Das Passiv in der wogulischen Sprache // JSFOu. 1960, 62. P. 1-34.

Malchukov 1993 - Malchukov A. Adversative constructions in Even in relation to passive and permissive // Causatives and Transitivity / Eds. B. Comrie, M. Polinsky. Amsterdam — Philadelphia, 1993. P. 369-384.

Nikolaeva 2001 - Nikolaeva I. Secondary topic as a relation in discourse // Lingustics. 2001, 39 (1). P. 1- 49.

Schiefer 1985 - Schiefer E. Das Passiv und der mediale Gebrauch passiver Formen im Obugrischen // Ars Ob-Ugrica. Vol. 6. München, 1985.

Shibatani 1985 - Shibatani M. Passives and related constructions: A prototype analysis // Language. 1985, 61 (4). P. $821-848$.

Skribnik 2001 - Skribnik E. Pragmatic structuring in Northern Mansi // CIFU 9. Pars VI: Dissertationes sectionum: Linguistica III / Ed. T. Seilenthal. Tartu, 2001. P. 222-239.

Toyota 2011 - Toyota J. The Grammatical Voice in Japanese: A Typological Perspective. Cambridge, 2011.

Tsuboi 2010 - Tsuboi E. Malefactivity in Japanese // Benefactives and malefactives. Typological perspectives and case studies. Amsterdam — Philadelphia, 2010. P. 419-435.

Virtanen 2012 - Virtanen S. Variation in three-participant constructions in Eastern Mansi // Linguistica Uralica. $2012,2$. P. 120-130.

Virtanen 2014 - Virtanen S. Pragmatic direct object marking in Eastern Mansi // Linguistics. 2014, 52 (2). P. 391 - 413.

Virtanen 2015 - Virtanen S. Transitivity in Eastern Mansi. PhD thesis. Helsinki, 2015.

Wierzbicka 1979 - Wierzbicka A. Are grammatical categories vague or polysemous? (The Japanese 'adversative' passive in a typological context) // Paper in Linguistics. 1979. Vol. 12. Iss. 1-2. P. 111-162. 